\title{
Carbohydrate-Restriction with High-Intensity Interval Training: An Optimal Combination for Treating Metabolic Diseases?
}

\author{
Monique E. Francois ${ }^{1}$, Jenna B. Gillen ${ }^{2}$ and Jonathan P. Little ${ }^{1 *}$ \\ ${ }^{1}$ University of British Columbia Okanagan, Kelowna, BC, Canada, ${ }^{2}$ University of Toronto, Toronto, ON, Canada
}

OPEN ACCESS

Edited by:

Gareth A. Wallis,

University of Birmingham,

United Kingdom

Reviewed by:

Sam Shepherd,

Liverpool John Moores University,

United Kingdom

Chris Shaw,

Deakin University, Australia

${ }^{*}$ Correspondence:

Jonathan P. Little

jonathan.little@ubc.ca

Specialty section: This article was submitted to Sport and Exercise Nutrition, a section of the journal

Frontiers in Nutrition

Received: 09 August 2017 Accepted: 27 September 2017 Published: 12 October 2017

Citation:

Francois ME, Gillen JB and Little JP (2017) Carbohydrate-Restriction with

High-Intensity Interval Training: An Optimal Combination for

Treating Metabolic Diseases?

Front. Nutr. 4:49.

doi: 10.3389/fnut.2017.00049
Lifestyle interventions incorporating both diet and exercise strategies remain cornerstone therapies for treating metabolic disease. Carbohydrate-restriction and high-intensity interval training (HIIT) have independently been shown to improve cardiovascular and metabolic health. Carbohydrate-restriction reduces postprandial hyperglycemia, thereby limiting potential deleterious metabolic and cardiovascular consequences of excessive glucose excursions. Additionally, carbohydrate-restriction has been shown to improve body composition and blood lipids. The benefits of exercise for improving insulin sensitivity are well known. In this regard, HIIT has been shown to rapidly improve glucose control, endothelial function, and cardiorespiratory fitness. Here, we report the available evidence for each strategy and speculate that the combination of carbohydrate-restriction and HIIT will synergistically maximize the benefits of both approaches. We hypothesize that this lifestyle strategy represents an optimal intervention to treat metabolic disease; however, further research is warranted in order to harness the potential benefits of carbohydrate-restriction and HIIT for improving cardiometabolic health.

Keywords: high-intensity interval training, glycemic control, metabolism, cardiometabolic disease, exercise, low-carb diets

\section{INTRODUCTION}

Type 2 diabetes (T2D) is one of the fastest growing, yet largely preventable chronic diseases worldwide (1). In addition to the hallmark feature of impaired glucose control, progression of T2D presents with a number of co-morbidities, increasing risk of premature mortality. Of particular concern is the high prevalence of atherosclerotic cardiovascular disease (CVD), which accounts for $\sim 80 \%$ of T2D-related co-morbidities $(2,3)$. Furthermore, a clustering of cardiovascular risk factors tend to manifest well before the diagnosis of T2D, accelerating the progression of CVD (4). These risk factors include central obesity, hypertension, hyperglycemia, and dyslipidemia, collectively coined the metabolic syndrome (5). In addition, physical inactivity and/or low-cardiorespiratory fitness are emerging as important modifiable risk factors for CVD and T2D (6). Importantly, both exercise and dietary strategies can help prevent, or slow the progression of, T2D-related co-morbidities. In this regard, lifestyle interventions incorporating both diet and exercise prescriptions remain at the frontline of therapeutic options for treating metabolic disease (7-9).

The main treatment goal of metabolic diseases, including T2D and the metabolic syndrome, is the prevention of atherosclerotic CVD $(10,11)$. To date, management of T2D and associated 
co-morbidities depends upon pharmacological interventions and the implementation of lifestyle changes $(9,11)$. Generally, public health guidelines encourage weight loss by recommending a calorie-restricted diet that is low in fat and added sugar, as well as performing at least $150 \mathrm{~min}$ of moderate-intensity physical activity each week $(10,11)$. While this general approach may be effective for the prevention of T2D (12), it does not appear to prevent, or alleviate, the burden of CVD in those with overt T2D [(8), LOOK Ahead trial]. Given the significant burden of CVD and diabetes-related co-morbidities, novel intervention strategies that can reduce cardiovascular risk factors, while imposing minimal side effects, are urgently sought after.

In the growing field of health and exercise science, a number of lifestyle approaches are currently gaining momentum. For example, dietary modifications such as carbohydrate-restriction and timerestricted feeding (including intermittent fasting) are emerging as alternative treatment strategies for persons with, and at risk for, metabolic diseases. Likewise, novel exercise prescriptions including high-intensity interval training (HIIT), and the concept of breaking up sedentary time with light physical activity, have revealed significant promise for improving or mitigating the deleterious effects of an inactive lifestyle. Innovative and effective strategies such as these have reaffirmed the strong influence of lifestyle modification on metabolic disease progression. While some of these individual approaches are beginning to inform public health guidelines (9), it is our belief that combining both diet and exercise modification will synergistically aid in the management of metabolic disease. In this regard, carbohydrate-restriction is loosely defined as restricting carbohydrates to less than $30 \%$ of caloric intake, and HIIT is characterized by brief periods of high-intensity exercise interspersed with low-intensity exercise for recovery. We acknowledge there are several other promising lifestyle interventions that we have not mentioned, however, the focus of this paper is to highlight the propensity for synergistic effects when carbohydrate-restriction and HIIT are combined. As with any lifestyle intervention, adherence is critical, and behavior change research on how to implement and support both HIIT and carbohydrate-restriction is needed. Initial work on adherence to HIIT is showing promise (13) and low-CHO diets appear to have similar adherence to other diets (14), but it will be necessary to assess the tolerability and adherence to our hypothesized approach moving forward.

\section{HYPOTHESIS}

In light of recent evidence, we hypothesize that the novel combination of a carbohydrate-restricted diet and HIIT represents a promising lifestyle strategy for the treatment of T2D. The purpose of this Hypothesis \& Theory piece is to briefly summarize the evidence that supports the individual therapeutic benefits of carbohydrate-restriction and HIIT, as well as present the idea that combining these approaches may represent the most potent lifestyle therapy for this costly disease.

\section{CARBOHYDRATE-RESTRICTION IN T2D}

Due to the growing prevalence of metabolic disease and the apparent ineffectiveness of the current dietary guidelines
$(15,16)$, alternative dietary approaches need to be considered. There is increasing evidence from scientific research [reviewed in Ref. (17)] and patient groups (UK Diabetes low-carb initiative; www.diabetes.org.uk) to support carbohydrate-restriction as a primary dietary treatment strategy for individuals with T2D. It has long been known that a diet high in carbohydrate elevates postprandial hyperglycemia and insulin responses, together accelerating the progression of T2D and atherosclerotic CVD (18-20). To this end, diets low in carbohydrate was recommended for T2D in 1800 s and during the early twentieth century. More recently, lowcarbohydrate diets are recognized in the ADA medical nutrition therapy guidelines (21) although the official dietary guidelines for individuals with T2D still do not advocate a low-carbohydrate approach. In comparison with standard low-fat caloric restrictive dietary interventions, energy-matched diets that restrict carbohydrates to $<30 \mathrm{~g}$ /day have been shown to result in greater reductions in $\mathrm{HbA}_{1 \mathrm{c}}$ and fat mass $(22,23)$, as well as superior improvements in the blood lipid profile $(24,25)$. Typically, lowcarbohydrate diets are not explicitly prescribed to be hypocaloric, but due to the satiating effects of protein and fat, energy intake is often lower $(22,26-28)$. However, while the energy intake is reduced relative to participant's habitual intake or when a low-fat diet is prescribed, low-carbohydrate diets reduce energy intake relative to energy requirements (26-28). For example, Boden et al. (26) observed a 1,027 cal/day reduction in energy intake when patients with T2D followed an ad libitum low-carbohydrate diet for 14 days; interestingly, the energy intake was reduced to a level that was appropriate to their weight. Moreover, the benefits of low-carbohydrate diets can occur without weight loss $(29,30)$. For a comprehensive review of carbohydrate-restriction for the management of T2D, an interested reader is directed to Feinman et al. (28).

While optimal guidelines for carbohydrate-restriction are not established, a carbohydrate-restrictive diet generally constitutes $<30 \%$ of caloric intake from carbohydrate food-sources (approximating $<130 \mathrm{~g} /$ day) (31). Very low-carbohydrate diets on the other hand, often referred to as ketogenic diets, involve more extreme reductions in carbohydrate of less than $\sim 30 \mathrm{~g} /$ day to permit nutritional ketosis (32). The optimal amount of carbohydrate in the diet (degree of carbohydrate-restriction) likely depends on the state of insulin resistance of the individual. For example, Cornier et al. (33) reported greater weight loss in insulin-sensitive individuals following a high- compared with a low-carbohydrate hypocaloric diet, whereas the opposite was true for insulin-resistant individuals (i.e., greater weight loss and improved insulin sensitivity on a low-carbohydrate hypocaloric diet). The implications of this study are noteworthy, given that more than $35 \%$ of adults are insulin resistant (34). Therefore, speculatively, more insulin-resistant individuals, particularly those with $\mathrm{T} 2 \mathrm{D}$, may require greater degrees of carbohydraterestriction for diet-induced improvements in metabolic health.

In longer-term interventions, a carbohydrate-restricted diet appears highly effective at promoting weight loss in patients with T2D $(25,27,35)$. This dietary strategy has also been shown to reduce visceral adiposity $(22,27,36)$, and lower medication requirements in adults with $\mathrm{T} 2 \mathrm{D}(25,37)$. Such reductions in central adiposity, insulin resistance, and hyperglycemia are 
central to preventing the development of CVD (38). Importantly, even in the absence of weight loss, carbohydrate-restrictive diets have also been shown to improve glycemic control $(29,39)$. For example, Gannon and colleagues found that despite no change in total body mass, an isocaloric diet comprising 30\% protein, $50 \%$ fat, and $20 \%$ carbohydrate reduced $\mathrm{HbA}_{1 \mathrm{c}}$ by $2 \%$ (absolute reduction) and improved fasting and postprandial blood glucose control in patients with T2D $(30,40)$. Such improvements in glucose control in the absence of weight loss may be due to improved insulin sensitivity and/or beta-cell function. Indeed, Boden et al. (26) showed that just 2 weeks of an isocaloric low-carbohydrate diet improves insulin sensitivity by $75 \%$ in T2D individuals, using the gold standard hyperinsulinemic euglycemic clamp technique. Although we are unaware of any direct evidence for improved beta-cell function with carbohydrate-restriction in individuals with T2D, associative evidence supports that providing beta-cell rest by removing hyperglycemia can reverse the insulin secretory defects present in animal models of T2D $(41,42)$.

\section{EXERCISE IN T2D: IT IS A HIIT!}

Physical inactivity presents one of the greatest public health concerns of our time (43). Indeed inactivity, or perhaps more accurately termed insufficient physical activity, is the fourth leading cause of death (44). Physical activity is broadly defined as any bodily movement produced by skeletal muscle, encompassing both activities of daily living and structured exercise. Exercise is defined as purposeful physical activity carried out to sustain or improve health or fitness, and if provided in a sufficient stimulus (dependent upon intensity and duration) is very effective to improve cardiometabolic health (45). The protective and therapeutic effects of regular exercise for the prevention of many chronic diseases are well-established and have been comprehensively reviewed by Pedersen and Saltin (46).

In order to achieve such health benefits, it is recommended that $150 \mathrm{~min}$ of moderate-to-vigorous intensity physical activity be performed each week. Perhaps one of the greatest health benefits of a regular exercise regimen is an improvement in cardiorespiratory fitness (47). Indeed, improving cardiorespiratory fitness is associated with a lower risk of both all-cause and CVD mortality $(48,49)$. The positive relationship between regular exercise and improvements in cardiorespiratory fitness appears to be intensity-dependent, however, with higher intensity exercise conferring larger improvements in fitness $(50,51)$. In fact, several systematic reviews and meta-analyses have reported that in comparison with moderate-intensity exercise, exercise performed at a higher intensity elicits greater improvements in markers of cardiovascular, and metabolic health in individuals with T2D (52-55). In agreement, a recent review by Baldi et al. (56), suggested that even public health guidelines, which recommend moderate-intensity continuous training (MICT), may not provide a sufficient stimulus for improving cardiovascular function. Thus, performing exercise at a vigorous intensity (relative to the individuals baseline fitness level) may be required to improve cardiovascular and metabolic health (57).

High-intensity interval training, which involves alternating periods of relatively intense exercise with periods of rest or low-intensity exercise for recovery $(58,59)$, is an attractive strategy enabling vigorous-intensity exercise to be incorporated in an exercise program. In comparison with MICT, HIIT is performed in an intermittent pattern, which results in only brief periods of relatively high-intensity effort, followed by recovery periods. Importantly, HIIT is a highly potent strategy to improve cardiorespiratory fitness (59). Indeed, a recent meta-analysis reported that HIIT-induced improvements in cardiorespiratory fitness were nearly one metabolic equivalent $(+3 \mathrm{ml} / \mathrm{kg} / \mathrm{min}$ ) higher than in response to MICT in individuals with lifestyle induced chronic disease (59). Improvements of this magnitude correspond to a $\sim 15 \%$ greater risk reduction for CVD morality (49), highlighting the potency of HIIT for reducing cardiovascular risk.

Various iterations of HIIT have been tested in small trials of T2D patients with reported benefits to cardiorespiratory fitness, glucose control, hepatic fat, vascular function, and body composition. While direct comparisons with standard care MICT are less common, recent investigations have reported superior improvements in many of these risk factors following HIIT (59-61). For example, an HIIT protocol involving $4 \times 4$ min intervals at $\sim 90 \%$ of maximal aerobic capacity, interspersed with 3 min of recovery has consistently yielded superior cardiovascular adaptations compared with an energy-matched MICT protocol. Following 12 weeks of training, endothelial function $(62,63)$, diastolic and systolic function (63) as well as cardiorespiratory fitness (62-64) were improved to a greater extent following HIIT compared with MICT.

Given the prevailing hyperglycemia among patients with T2D, the impact of HIIT on glycemic control has received much attention (63-66). In a landmark study, Karstoft et al. $(65,67)$ compared 60 min of interval-walking 5 days per week, to an energy-expenditure matched continuous-walking protocol in T2D. The interval-walking group performed 3 min periods of fast walking (above $70 \% \mathrm{VO}_{2}$ peak), followed by $3 \mathrm{~min}$ of slow walking (below 70\% $\mathrm{VO}_{2}$ peak) for 60 min three times per week, while the continuous protocol involved $60 \mathrm{~min}$ of walking at $55 \%$ $\mathrm{VO}_{2}$ peak. Following 16 weeks of training, the interval-walking group displayed greater reductions in mean 24-h blood glucose concentration assessed with continuous glucose monitoring, which were accompanied by superior improvements in cardiorespiratory fitness and body composition. In a follow-up publication in the same participants, authors reported improved insulin sensitivity in the interval-walking group only, as measured by hyperglycemic clamp with glucose tracers. These superior improvements in glucose control are reinforced by a recent metaanalysis demonstrating that HIIT improves fasting blood glucose and $\mathrm{HbA}_{\mathrm{Ic}}$ to a greater extent than MICT in individuals at risk for, or afflicted with, T2D (60). Specifically, in those with T2D, HIIT was found to lower fasting glucose and $\mathrm{HbA}_{\mathrm{lc}}$ by $0.92 \mathrm{mmol} / \mathrm{l}$ and $0.5 \%$, respectively, which is of comparable magnitude to pharmacological-induced improvements in glycemia (68). The pronounced improvements in glucose control following HIIT are likely mediated by many factors, some of which may include greater beta-cell function $(67,69)$, improved skeletal muscle insulin signaling $(62,67)$, and reductions in total body $(62,64,65)$ and hepatic $(66,70)$ fat content. 
While these findings are compelling, the time commitment associated with many HIIT protocols is often higher (150$300 \mathrm{~min} /$ week) than that obtained by the general population, which questions whether such exercise is attainable for many individuals who report a "lack of time" as a barrier to regular exercise (71). With this in mind, low-volume HIIT protocols involving a reduced exercise volume and time commitment may represent a viable strategy. We have previously shown that 2 weeks of HIIT involving six sessions of $10 \times 60$ s cycling intervals at $\sim 90 \%$ of maximal heart rate, interspersed with $60 \mathrm{~s}$ of rest, improved 24-h mean blood glucose concentration, and lowered postprandial glucose excursions in patients with T2D (72). Using this same protocol, Madsen et al. (69) reported a $0.5 \%$ reduction in $\mathrm{HbA}_{1 \mathrm{c}}$ and increased glucose tolerance and beta-cell function after 8 weeks of training in T2D. In addition to improvements in glycemic control, we (73) and others (74) have reported increases in cardiorespiratory fitness and total body lean mass as well as reductions in body fat following 12 weeks of low-volume HIIT in patients with T2D. These findings are quite intriguing, given that total exercise time was only $~ 30 \mathrm{~min} /$ week within a 75 -min weekly time commitment. Importantly, low-volume HIIT has been reported to be enjoyable $(13,75,76)$, which may be attributable to the low-time commitment and/or short interval duration (77).
The mechanisms by which HIIT improves metabolic and cardiovascular health are likely multifaceted, and may relate to the high rates of muscle fiber recruitment, rapid muscle glycogen depletion, and repetitive shear stress during exercise $(78,79)$. The intermittent cardiorespiratory and metabolic demands imposed also appear to be important in regulating chronic adaptations to HIIT (79). Indeed, it has been suggested that training with alternating intensity, and not solely measuring training volume and mean intensity, is important for improving cardiovascular and metabolic health in individuals with T2D $(65,67,80)$.

\section{COMBINING CARBOHYDRATE- RESTRICTION AND HIIT FOR IMPROVED CARDIOMETABOLIC HEALTH}

While the independent improvements in cardiometabolic health following carbohydrate-restriction and HIIT have been well investigated, the combined impact of these lifestyle strategies in patients with T2D has yet to be explored. It is our hypothesis that supplementing a carbohydrate-restrictive diet with HIIT, or likewise, strategically limiting carbohydrate availability during HIIT, may enhance the therapeutic effects of either intervention alone (Figure 1). Specifically, we believe that a combined

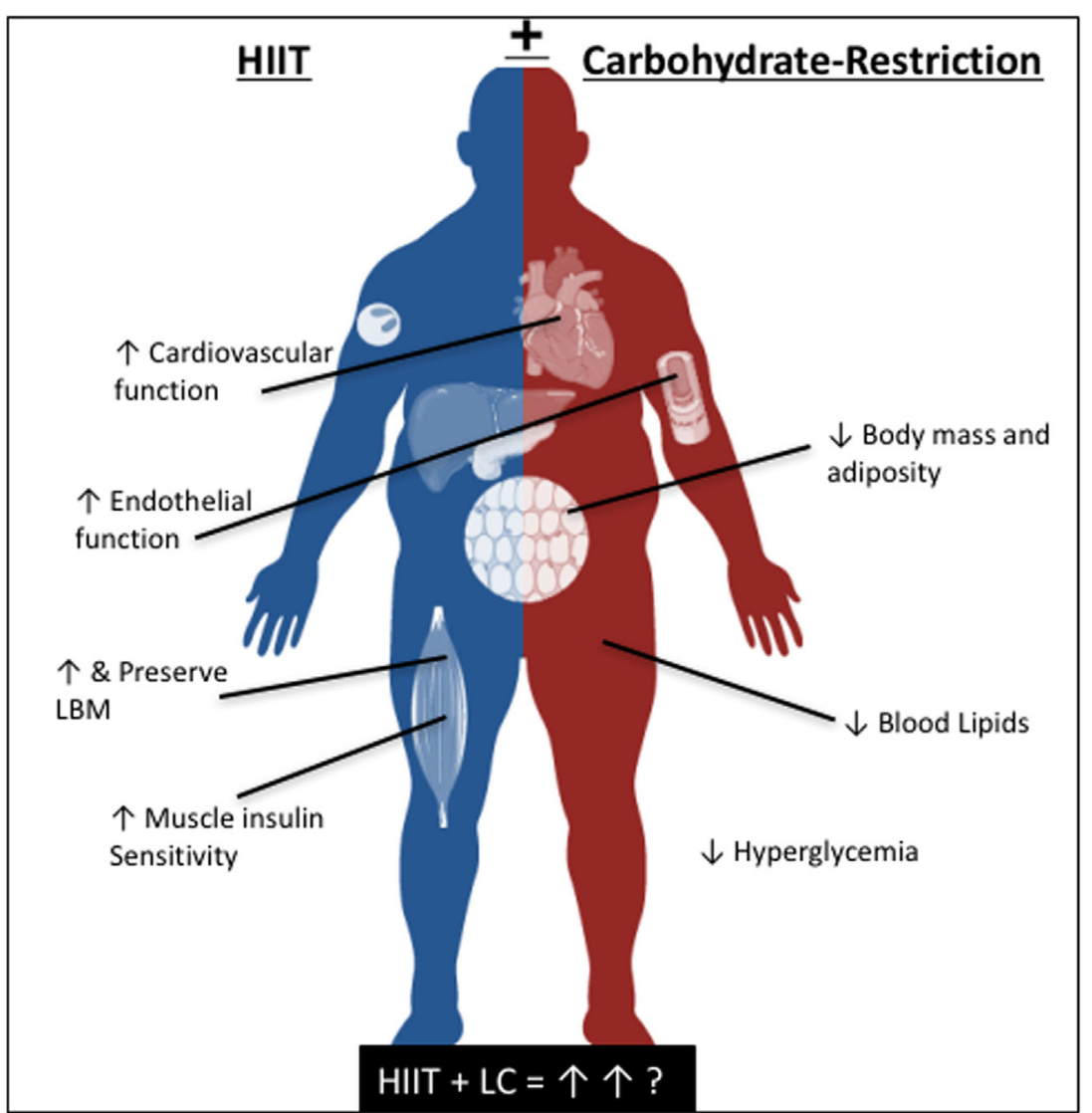

FIGURE 1 | The independent, and proposed reciprocal benefits of high-intensity interval training and carbohydrate-restriction for cardiometabolic health. 
approach will synergistically improve the acute and chronic regulation of glycemic control and endothelial function while maximally improving cardiorespiratory fitness, resulting in the optimal lifestyle strategy to limit the progression of T2D, and related co-morbidities.

\section{Adding HIIT to a Carbohydrate-Restrictive Diet}

While a carbohydrate-restrictive diet effectively reduces hyperglycemic excursions and improves glycemic control in patients with T2D $(29,39)$, a perceived limitation of this dietary approach is that it is inevitably higher in dietary fat. Studies in rodents (81, 82) and epidemiology evidence in humans suggests that a highfat diet (which is also low in carbohydrate) promotes insulin resistance $(83,84)$. Specifically, it appears that in the short-term, high-fat diets (for $\leq 1$ week) in humans may impair glucose tolerance (when tested by providing a high-glucose load), at least from trials in healthy adults $(85,86)$. In healthy insulin-sensitive participants, a reduction in insulin sensitivity and/or glucose tolerance following a switch to a low-carbohydrate high-fat diet is likely an adaptive response as the body transitions over to higher baseline fat utilization $(87,88)$. However, individuals with obesity and insulin resistance experience some degree of metabolic inflexibility; an inability to modulate daily fat and carbohydrate oxidation based upon substrate availability (89). Consequently, exaggerated blood glucose and lipid responses to meals are prevalent in individuals with insulin resistance (90). This suggests that if one is to follow a low-carbohydrate diet, it must be followed consistently (i.e., no "cheating" or consumption of high-glycemic index foods) or that exercise should be incorporated to mitigate any detrimental effects on insulin sensitivity. Indeed, the most important determinant of the effectiveness of dietary interventions is adherence (91). However, we have shown that a single session of low-volume HIIT performed after breakfast lowers postprandial glucose excursions throughout the day in patients with T2D (92) and "small snacks" of interval exercise distributed before meals significantly lowers postprandial hyperglycemia and mean glucose concentration over $24 \mathrm{~h}$ (93). Therefore, exercise, of a sufficient stimulus, strategically timed to dispose of postprandial glucose and/or to increase fat utilization is a highly effective strategy to reduce postprandial excursions. In considering the glycemic response to a meal is primarily determined by the quantity and type of carbohydrate (94), restricting carbohydrate inevitably will lower postprandial glucose and insulin excursions $(95,96)$. Thus, it would appear that the combination of carbohydrate-restriction with HIIT may promote synergistic improvements for acutely reducing postprandial glucose spikes, increasing muscle glucose uptake, and augmenting insulin sensitivity.

Furthermore, exercising before or after a high-fat meal has been shown to ameliorate the detrimental effects on endothelial function (97-99). Endothelial function is an important prognostic indicator of cardiovascular health as the endothelium is the barrier protecting the artery from thrombosis, inflammation, and stiffening $(100,101)$. Postprandial increases in lipids and glucose are independent risk factors for CVD (102). The postprandial impairment in endothelial function may be related to excessive postprandial hypertriglyceridemia, inflammation, and oxidative stress following the meal $(103,104)$. Given that several studies have supported the notion that "high-fat" meals [which are often also high in refined carbohydrate (105-107)] can promote endothelial dysfunction, there appears to be some apprehension around adopting a low-carbohydrate high-fat diet. However, this is despite the fact that high-carbohydrate meals can elicit similar dysmetabolism and endothelial dysfunction (105). Regardless, if a typical low-carbohydrate high-fat meal does acutely impair endothelial function this may not be an ideal strategy for participants at elevated CVD risk. However, Tyldum et al. (99) reported that a single bout of HIIT, but not MICT, performed $\sim 16-\mathrm{h}$ prior to a high-fat meal protected against endothelial dysfunction. Interestingly, this was tightly related to exercise-induced increases in antioxidant capacity with HIIT, as measured by the colorimetric total antioxidant capacity assay (99). Tjønna et al. (108) also showed that endothelial function and nitric oxide bioavailability were increased $\sim 72 \mathrm{~h}$ after an acute session of HIIT in individuals with T2D. Collectively, it appears that exercise can negate the detrimental effects of a high-fat meal on endothelial function, with HIIT as a promising strategy to improve endothelial function. Therefore, strategically timing HIIT sessions could reduce any potential negative effects of low-carbohydrate high-fat meals that are often incorporated into carbohydrate-restricted meal plans.

Lastly, over the long term, reductions in fat mass and increases in lean mass appear critical for sustained improvements in metabolic health following lifestyle interventions (109, 110). In this regard, the combination of diet and exercise may be superior for preserving lean mass and reducing body fat in patients with T2D $(111,112)$. Energy restriction interventions, in the absence of exercise, often result in the loss of lean body mass in addition to fat loss $(113,114)$. Given the strong relationship between lean body mass, metabolic health, and functional capacity (115), preserving lean body mass with exercise during any energy-restricted diet (whether low-carbohydrate or not) is of primary importance. Moreover, preserving lean body mass in individuals with T2D is particularly important given the accelerated loss of skeletal muscle with insulin resistance, and the concomitant worsening of glycemic control with decreased skeletal muscle mass $(116,117)$. In view of this, HIIT has recently been shown to increase skeletal muscle protein synthesis of young and older adults, an effect linked to improved insulin sensitivity, and mitochondrial function (118). Relative to MICT and resistance training, HIIT resulted in the greatest increase in gene expression for mitochondrial function, muscle growth, and insulin signaling pathways in older adults (118). In both obese adults and those with and T2D, HIIT has been shown to reduce fat mass and increase lean mass $(62,64,65,69,73,74)$. Although the impact of a low-carbohydrate diet combined with HIIT has not been adequately studied, there is evidence that a low-carbohydrate diet promotes favorable changes in body composition when combined with resistance training in women with obesity (119). Thus, the combination of HIIT with a lowcarbohydrate diet may help to preserve or increase lean mass in individuals with T2D. 


\section{EXERCISE AND NUTRIENT INTERACTIONS: ADDING CARBOHYDRATE-RESTRICTION TO HIIT}

It is well known that nutrient ingestion in-and-around the exercise period impacts the molecular signaling and thus metabolic responses to exercise (120). Accumulating evidence has revealed that nutrient availability, in addition to exercise components (e.g., mode, intensity, and duration), play a putative role in determining the adaptive response to exercise training (121). Indeed energy status (whether surplus or deficit) has been shown to modify the neuroendocrine, acute molecular signaling, and gene transcription response to exercise $(121,122)$. For example, low-skeletal muscle glycogen prior to exercise augments AMPK signaling and up-regulates the transcription of PGCla and mitochondrial enzymes (123-125). It has also been suggested that delaying glycogen restoration after exercise may enhance the adaptive response for proteins involved in glucose uptake (i.e., glucose transporter GLUT-4) (126, 127). Therefore, restricting carbohydrates and/or training fasted may increase the adaptive (i.e., training-induced increase in metabolic signaling) response to exercise $(121,128,129)$. In contrast, providing carbohydrate in proximity to exercise can in fact blunt the activation of key regulatory genes for metabolizing fat postexercise (123). Thus, it is tempting to speculate that combining HIIT with a lowcarbohydrate diet in T2D could enhance molecular signaling and metabolic adaptations in skeletal muscle.

In support of this, Newsom et al. (130) reported that an energy deficit after exercise does not contribute to the exercised-induced improvements in insulin sensitivity if ample carbohydrate is provided. However, withholding carbohydrate (but providing ample energy) postexercise resulted in improved insulin sensitivity the following day. Furthermore, restricting carbohydrate before and between interval training sessions has been shown to augment the cellular signaling and upregulate skeletal muscle metabolic enzyme adaptations in young healthy participants $(131,132)$. This suggests that strategically restricting carbohydrate during HIIT could potentiate exercise-induced skeletal muscle adaptations in patients with T2D. To our knowledge, however, this strategy has not been examined in clinical populations. In the only study we are aware of, Sartor et al. (133) reported increased resting fat oxidation and cardiorespiratory fitness following a 2-week HIIT plus carbohydrate-restricted diet intervention in obese men. However, changes in insulin sensitivity and glucose control were not reported and thus future long-term studies are warranted.

\section{PERSPECTIVES FOR FUTURE RESEARCH}

Carbohydrate-restriction and HIIT have independently been shown to improve several indices of cardiometabolichealth. Taken together, it is our opinion that an adjunct therapy incorporating both carbohydrate-restriction and HIIT would be a particularly effective treatment for metabolic and CVDs (Figure 1). However promising, several key questions require further research, namely (i) the level of carbohydrate-restriction that is effective, safe, and feasible for different individuals over the long-term and (ii) the most effective HIIT protocol to complement a carbohydraterestrictive diet. For example, low-volume HIIT protocols have been shown to improve a host of cardiometabolic risk factors, and are well-tolerated and enjoyed by individuals with T2D (13, $70,73)$, however, future research on the integration of HIIT with carbohydrate-restriction is needed. In this regard, using rating of perceived exertion as an indication of exercise intensity may be more appropriate than heart rate (70) given the tolerance to HIIT during carbohydrate-restriction may be reduced. Sartor et al. (133) showed promising effects of carbohydrate-restriction with interval training ( $4 \times 4$-min intervals) over 14 days in obese individuals. However, further research is needed in this area to determine the exercise dose that is feasible and well-tolerated during carbohydrate-restriction. In this regard and with the advancement of personalized and precision medicine, the development of an algorithm that could be used to adjust the level of carbohydrate-restriction and corresponding HIIT protocol according to age, underlying insulin resistance, fitness, preference, and genetics could prove useful. Considering there are many effective HIIT protocols, the "optimal" protocol may in fact be based on preference rather than physiology.

\section{CONCLUSION: HIIT WITH CARBOHYDRATE-RESTRICTION: AN OPTIMAL COMBINATION FOR INDIVIDUALS WITH T2D?}

We hypothesize that the combination of HIIT with a carbohydraterestrictive diet may be the most effective strategy to reduce hyperglycemia, improve insulin sensitivity, promote favorable changes in body composition, and preserve (or increase) endothelial function in patients with T2D. While the combination of diet and exercise for the treatment of T2D is self-evident, the optimal combination is yet to be determined. Strategically timing HIIT in proximity to low-carbohydrate high-fat meals may synergistically maximize the benefits of both approaches, as well as minimize any potential negative effects of postprandial lipemia if one is following a low-carbohydrate highfat diet. Such a strategy is indeed testable and warranted to improve cardiometabolic health and reduce cardiovascular risk in T2D.

\section{AUTHOR CONTRIBUTIONS}

MF, JG, and JL contributed to the ideas and hypotheses presented in this manuscript; drafted, revised, and edited the manuscript.

\section{FUNDING}

JBG is supported by a CIHR Postdoctoral Research Fellowship. JPL is supported by a CIHR New Investigator Award (MSH141980) and MSFHR Scholar Award (16890). 


\section{REFERENCES}

1. Guariguata L, Whiting D, Hambleton I, Beagley J, Linnenkamp U, Shaw J. Global estimates of diabetes prevalence for 2013 and projections for 2035. Diabetes Res Clin Pract (2014) 103(2):137-49. doi:10.1016/j.diabres.2013.11.002

2. Laakso M. Hyperglycemia and cardiovascular disease in type 2 diabetes. Diabetes (1999) 48(5):937-42. doi:10.2337/diabetes.48.5.937

3. Fox CS, Coady S, Sorlie PD, D’Agostino RB, Pencina MJ, Vasan RS, et al. Increasing cardiovascular disease burden due to diabetes mellitus the Framingham Heart Study. Circulation (2007) 115(12):1544-50. doi:10.1161/ CIRCULATIONAHA.106.658948

4. Haffner SM, Stern MP, Hazuda HP, Mitchell BD, Patterson JK. Cardiovascular risk factors in confirmed prediabetic individuals: does the clock for coronary heart disease start ticking before the onset of clinical diabetes? JAMA (1990) 263(21):2893-8. doi:10.1001/jama.263.21.2893

5. Alberti KG, Zimmet PZ. Definition, diagnosis and classification of diabetes mellitus and its complications. Part 1: diagnosis and classification of diabetes mellitus. Provisional report of a WHO consultation. Diabet Med (1998) 15(7):539-53. doi:10.1002/(SICI)1096-9136(199807)15:7<539::AIDDIA668 $>3.0 . \mathrm{CO} ; 2-\mathrm{S}$

6. Warburton DE, Nicol CW, Bredin SS. Health benefits of physical activity: the evidence. Can Med Assoc J (2006) 174(6):801-9. doi:10.1503/cmaj.051351

7. Diabetes Prevention Program Research Group, Knowler WC, Fowler SE, Hamman RF, Christophi CA, Hoffman HJ, et al. 10-year follow-up of diabetes incidence and weight loss in the Diabetes Prevention Program Outcomes Study. Lancet (2009) 374(9702):1677-86. doi:10.1016/S0140-6736(09)61457-4

8. Wing R, Bolin P, Brancati F, Bray G, Clark J, Coday M, et al. Cardiovascular effects of intensive lifestyle intervention in type 2 diabetes. $N$ Engl J Med (2013) 369(2):145-54. doi:10.1056/NEJMoa1212914

9. Colberg SR, Sigal RJ, Yardley JE, Riddell MC, Dunstan DW, Dempsey PC, et al. Physical activity/exercise and diabetes: a position statement of the American Diabetes Association. Diabetes Care (2016) 39(11):2065-79. doi: $10.2337 / \mathrm{dc} 16-1728$

10. Grundy SM, Cleeman JI, Daniels SR, Donato KA, Eckel RH, Franklin BA, et al. Diagnosis and management of the metabolic syndrome. Circulation (2005) 112(17):2735-52. doi:10.1161/CIRCULATIONAHA.105.169405

11. Inzucchi SE, Bergenstal R, Buse JB, Diamant M, Ferrannini E, Nauck M, et al. Management of hyperglycaemia in type 2 diabetes: a patient-centered approach. Position statement of the American Diabetes Association (ADA) and the European Association for the Study of Diabetes (EASD). Diabetologia (2012) 55(6):1577-96. doi:10.1007/s00125-012-2534-0

12. Knowler WC, Barrett-Connor E, Fowler SE, Hamman RF, Lachin JM, Walker EA, et al. Reduction in the incidence of type 2 diabetes with lifestyle intervention or metformin. N Engl J Med (2002) 346:393-403. doi:10.1056/ NEJMoa012512

13. Jung ME, Bourne JE, Beauchamp MR, Robinson E, Little JP. High-intensity interval training as an efficacious alternative to moderate-intensity continuous training for adults with prediabetes. J Diabetes Res (2015) 2015:9. doi: $10.1155 / 2015 / 191595$

14. Hu T, Yao L, Reynolds K, Niu T, Li S, Whelton P, et al. Adherence to lowcarbohydrate and low-fat diets in relation to weight loss and cardiovascular risk factors. Obes Sci Pract (2016) 2(1):24-31. doi:10.1002/osp4.23

15. Kennedy ET, Bowman SA, Powell R. Dietary-fat intake in the US population. J Am Coll Nutr (1999) 18(3):207-12. doi:10.1080/07315724.1999.10 718853

16. Mokdad AH, Bowman BA, Ford ES, Vinicor F, Marks JS, Koplan JP. The continuing epidemics of obesity and diabetes in the United States. JAMA (2001) 286(10):1195-200. doi:10.1001/jama.286.10.1195

17. Noakes TD, Windt J. Evidence that supports the prescription of lowcarbohydrate high-fat diets: a narrative review. Br J Sports Med (2017) 51(2): 133-9. doi:10.1136/bjsports-2016-096491

18. Coulston AM, Hollenbeck CB, Swislocki AL, Chen YI, Reaven GM. Deleterious metabolic effects of high-carbohydrate, sucrose-containing diets in patients with non-insulin-dependent diabetes mellitus. Am J Med (1987) 82(2):213-20. doi:10.1016/0002-9343(87)90058-1

19. Garg A, Grundy SM, Koffler M. Effect of high carbohydrate intake on hyperglycemia, islet function, and plasma lipoproteins in NIDDM. Diabetes Care (1992) 15(11):1572-80. doi:10.2337/diacare.15.11.1572
20. Reaven GM. The role of insulin resistance and hyperinsulinemia in coronary heart disease. Metabolism (1992) 41(5):16-9. doi:10.1016/00260495(92)90088-R

21. American Diabetes Association. Nutrition recommendations and interventions for diabetes. Diabetes Care (2008) 31(Suppl 1):S61-78. doi:10.2337/dc08-S061

22. Samaha FF, Iqbal N, Seshadri P, Chicano KL, Daily DA, McGrory J, et al. A low-carbohydrate as compared with a low-fat diet in severe obesity. N Engl J Med (2003) 348(21):2074-81. doi:10.1056/NEJMoa022637

23. Volek JS, Sharman MJ, Gómez AL, Judelson DA, Rubin MR, Watson G, et al. Comparison of energy-restricted very low-carbohydrate and low-fat diets on weight loss and body composition in overweight men and women. Nutr Metab (2004) 1(1):13. doi:10.1186/1743-7075-1-13

24. Forsythe CE, Phinney SD, Fernandez ML, Quann EE, Wood RJ, Bibus DM, et al. Comparison of low fat and low carbohydrate diets on circulating fatty acid composition and markers of inflammation. Lipids (2008) 43(1):65-77. doi:10.1007/s11745-007-3132-7

25. Westman EC, Yancy WS, Mavropoulos JC, Marquart M, McDuffie JR. The effect of a low-carbohydrate, ketogenic diet versus a low-glycemic index diet on glycemic control in type 2 diabetes mellitus. Nutr Metab (2008) 5(1):36. doi:10.1186/1743-7075-5-36

26. Boden G, Sargrad K, Homko C, Mozzoli M, Stein TP. Effect of a lowcarbohydrate diet on appetite, blood glucose levels, and insulin resistance in obese patients with type 2 diabetes. Ann Intern Med (2005) 142(6):403-11. doi:10.7326/0003-4819-142-6-200503150-00006

27. Dyson P, Beatty S, Matthews D. A low-carbohydrate diet is more effective in reducing body weight than healthy eating in both diabetic and nondiabetic subjects. Diabet Med (2007) 24(12):1430-5. doi:10.1111/j.1464-5491. 2007.02290.x

28. Feinman RD, Pogozelski WK, Astrup A, Bernstein RK, Fine EJ, Westman EC, et al. Dietary carbohydrate restriction as the first approach in diabetes management: critical review and evidence base. Nutrition (2015) 31(1):1-13. doi:10.1016/j.nut.2014.06.011

29. Gannon MC, Nuttall FQ. Control of blood glucose in type 2 diabetes without weight loss by modification of diet composition. Nutr Metab (2006) 3(1):16. doi:10.1186/1743-7075-3-16

30. Nuttall FQ, Schweim K, Hoover H, Gannon MC. Effect of the LoBAG 30 diet on blood glucose control in people with type 2 diabetes. Br J Nutr (2008) 99(03):511-9. doi:10.1017/S0007114507819155

31. Accurso A, Bernstein RK, Dahlqvist A, Draznin B, Feinman RD, Fine EJ, et al. Dietary carbohydrate restriction in type 2 diabetes mellitus and metabolic syndrome: time for a critical appraisal. Nutr Metab (2008) 5(1):9. doi:10.1186/1743-7075-5-9

32. Paoli A, Rubini A, Volek J, Grimaldi K. Beyond weight loss: a review of the therapeutic uses of very-low-carbohydrate (ketogenic) diets. Eur J Clin Nutr (2013) 67(8):789-96. doi:10.1038/ejcn.2013.116

33. Cornier MA, Donahoo WT, Pereira R, Gurevich I, Westergren R, Enerback S, et al. Insulin sensitivity determines the effectiveness of dietary macronutrient composition on weight loss in obese women. Obes Res (2005) 13(4):703-9. doi:10.1038/oby.2005.79

34. Centers for Disease Control and Prevention. National Diabetes Statistics Report: Estimates of Diabetes and Its Burden in the United States, 2014. Atlanta, GA: US Department of Health and Human Services (2014).

35. Stern L, Iqbal N, Seshadri P, Chicano KL, Daily DA, McGrory J, et al. The effects of low-carbohydrate versus conventional weight loss diets in severely obese adults: one-year follow-up of a randomized trial. Ann Intern Med (2004) 140(10):778-85. doi:10.7326/0003-4819-140-10-200405180-00007

36. Meckling KA, O'Sullivan C, Saari D. Comparison of a low-fat diet to a lowcarbohydrate diet on weight loss, body composition, and risk factors for diabetes and cardiovascular disease in free-living, overweight men and women. J Clin Endocrinol Metab (2004) 89(6):2717-23. doi:10.1210/jc.2003031606

37. Yancy WS, Westman EC, McDuffie JR, Grambow SC, Jeffreys AS, Bolton J, et al. A randomized trial of a low-carbohydrate diet vs orlistat plus a low-fat diet for weight loss. Arch Intern Med (2010) 170(2):136-45. doi:10.1001/ archinternmed.2009.492

38. Bianchi C, Miccoli R, Penno G, Del Prato S. Primary prevention of cardiovascular disease in people with dysglycemia. Diabetes Care (2008) 31(Suppl 2):S208-14. doi:10.2337/dc08-s256 
39. Gannon MC, Hoover H, Nuttall FQ. Further decrease in glycated hemoglobin following ingestion of a LoBAG 30 diet for 10 weeks compared to 5 weeks in people with untreated type 2 diabetes. Nutr Metab (2010) 7(1):64. doi:10.1186/1743-7075-7-64

40. Nuttall FQ, Almokayyad RM, Gannon MC. Comparison of a carbohydratefree diet vs. fasting on plasma glucose, insulin and glucagon in type 2 diabetes. Metabolism (2015) 64(2):253-62. doi:10.1016/j.metabol.2014.10.004

41. Alarcon C, Boland BB, Uchizono Y, Moore PC, Peterson B, Rajan S, et al. Pancreatic $\beta$-cell adaptive plasticity in obesity increases insulin production but adversely affects secretory function. Diabetes (2016) 65(2):438-50. doi:10.2337/db15-0792

42. Little JP, Myette-Côté É. Comment on Alarcon et al. Pancreatic $\beta$-cell adaptive plasticity in obesity increases insulin production but adversely affects secretory function. Diabetes 2016; 65: 438-450. Diabetes (2016) 65(8):e28. doi: $10.2337 / \mathrm{db} 16-0492$

43. Blair SN. Physical inactivity: the biggest public health problem of the 21st century. Br J Sports Med (2009) 43(1):1-2.

44. Kohl HW, Craig CL, Lambert EV, Inoue S, Alkandari JR, Leetongin G, et al. The pandemic of physical inactivity: global action for public health. Lancet (2012) 380(9838):294-305. doi:10.1016/S0140-6736(12)60898-8

45. Hawley JA, Hargreaves M, Joyner MJ, Zierath JR. Integrative biology of exercise. Cell (2014) 159(4):738-49. doi:10.1016/j.cell.2014.10.029

46. Pedersen BK, Saltin B. Exercise as medicine-evidence for prescribing exercise as therapy in 26 different chronic diseases. Scand J Med Sci Sports (2015) 25(S3):1-72. doi:10.1111/sms.12581

47. Kaminsky LA, Arena R, Beckie TM, Brubaker PH, Church TS, Forman DE, et al. The importance of cardiorespiratory fitness in the United States: the need for a national registry. Circulation (2013) 127(5):652-62. doi:10.1161/ CIR.0b013e31827ee100

48. Kodama S, Saito K, Tanaka S, Maki M, Yachi Y, Asumi M, et al. Cardiorespiratory fitness as a quantitative predictor of all-cause mortality and cardiovascular events in healthy men and women: a meta-analysis. JAMA (2009) 301(19): 2024-35. doi:10.1001/jama.2009.681

49. Lee D-C, Sui X, Artero EG, Lee I-M, Church TS, McAuley PA, et al. Longterm effects of changes in cardiorespiratory fitness and body mass index on all-cause and cardiovascular disease mortality in men. Circulation (2011) 124(23):2483-90. doi:10.1161/CIRCULATIONAHA.111.038422

50. Gormley SE, Swain DP, High R, Spina RJ, Dowling EA, Kotipalli US, et al. Effect of intensity of aerobic training on VO2max. Med Sci Sports Exerc (2008) 40(7):1336-43. doi:10.1249/01.mss.0000321629.41403.46

51. Ross R, de Lannoy L, Stotz PJ. Separate effects of intensity and amount of exercise on interindividual cardiorespiratory fitness response. Mayo Clin Proc (2015) 90:1506-14. doi:10.1016/j.mayocp.2015.07.024

52. Boulé NG, Haddad E, Kenny GP, Wells GA, Sigal RJ. Effects of exercise on glycemic control and body mass in type 2 diabetes mellitus: a meta-analysis of controlled clinical trials. JAMA (2001) 286(10):1218-27. doi:10.1001/ jama.286.10.1218

53. Boulé N, Kenny G, Haddad E, Wells G, Sigal R. Meta-analysis of the effect of structured exercise training on cardiorespiratory fitness in type 2 diabetes mellitus. Diabetologia (2003) 46(8):1071-81. doi:10.1007/s00125-003-1160-2

54. Snowling NJ, Hopkins WG. Effects of different modes of exercise training on glucose control and risk factors for complications in type 2 diabetic patients. Diabetes Care (2006) 29(11):2518-27. doi:10.2337/dc06-1317

55. Marwick TH, Hordern MD, Miller T, Chyun DA, Bertoni AG, Blumenthal RS, et al. Exercise training for type 2 diabetes mellitus. Circulation (2009) 119(25):3244-62. doi:10.1161/CIRCULATIONAHA.109.192521

56. Baldi JC, Wilson GA, Wilson LC, Wilkins GT, Lamberts RR. The type 2 diabetic heart: its role in exercise intolerance and the challenge to find effective exercise interventions. Sports Med (2016) 46(11):1-13. doi:10.1007/ s40279-016-0542-9

57. Garber CE, Blissmer B, Deschenes MR, Franklin BA, Lamonte MJ, Lee I-M, et al. Quantity and quality of exercise for developing and maintaining cardiorespiratory, musculoskeletal, and neuromotor fitness in apparently healthy adults: guidance for prescribing exercise. Med Sci Sports Exerc (2011) 43(7):1334-59. doi:10.1249/MSS.0b013e318213fefb

58. Gibala MJ, Little JP, MacDonald MJ, Hawley JA. Physiological adaptations to low-volume, high-intensity interval training in health and disease. J Physiol (2012) 590(5):1077-84. doi:10.1113/jphysiol.2011.224725
59. Weston KS, Wisløff U, Coombes JS. High-intensity interval training in patients with lifestyle-induced cardiometabolic disease: a systematic review and meta-analysis. Br JSports Med (2014) 48(16):1227-34. doi:10.1136/ bjsports-2013-092576

60. Jelleyman C, Yates T, O’Donovan G, Gray L, King JA, Khunti K, et al. The effects of high-intensity interval training on glucose regulation and insulin resistance: a meta-analysis. Obes Rev (2015) 16(11):942-61. doi:10.1111/ obr.12317

61. Ramos JS, Dalleck LC, Tjonna AE, Beetham KS, Coombes JS. The impact of high-intensity interval training versus moderate-intensity continuous training on vascular function: a systematic review and meta-analysis. Sports Med (2015) 45(5):679-92. doi:10.1007/s40279-015-0321-z

62. Tjønna AE, Lee SJ, Rognmo Ø, Stølen TO, Bye A, Haram PM, et al. Aerobic interval training versus continuous moderate exercise as a treatment for the metabolic syndrome. Circulation (2008) 118(4):346-54. doi:10.1161/ CIRCULATIONAHA.108.772822

63. Hollekim-Strand SM, Bjørgaas MR, Albrektsen G, Tjønna AE, Wisløff U, Ingul CB. High-intensity interval exercise effectively improves cardiac function in patients with type 2 diabetes mellitus and diastolic dysfunction. J Am Coll Cardiol (2014) 64(16):1758. doi:10.1016/j.jacc.2014.07.971

64. Støa EM, Meling S, Nyhus L-K, Strømstad G, Mangerud KM, Helgerud J, et al. High-intensity aerobic interval training improves aerobic fitness and HbAlc among persons diagnosed with type 2 diabetes. Eur J Appl Physiol (2017) 117(3):455-67. doi:10.1007/s00421-017-3540-1

65. Karstoft K, Winding K, Knudsen SH, Nielsen JS, Thomsen C, Pedersen BK, et al. The effects of free-living interval-walking training on glycemic control, body composition, and physical fitness in type 2 diabetic patients a randomized, controlled trial. Diabetes Care (2013) 36(2):228-36. doi:10.2337/ dc12-0658

66. Apostolopoulou M, Röhling M, Gancheva S, Jelenik T, Kaul K, Bierwagen A, et al. High-intensity interval training improves peripheral insulin sensitivity and mitochondrial respiration in patients with type 2 diabetes. Diabetol Stoffwechsel (2016) 11(S 01):FV8. doi:10.1055/s-0036-1580755

67. Karstoft K, Winding K, Knudsen SH, James NG, Scheel MM, Olesen J, et al. Mechanisms behind the superior effects of interval vs continuous training on glycaemic control in individuals with type 2 diabetes: a randomised controlled trial. Diabetologia (2014) 57(10):2081-93. doi:10.1007/ s00125-014-3334-5

68. Garber AJ, Duncan TG, Goodman AM, Mills DJ, Rohlf JL. Efficacy of metformin in type II diabetes: results of a double-blind, placebo-controlled, dose-response trial. Am J Med (1997) 103(6):491-7. doi:10.1016/S00029343(97)00254-4

69. Madsen SM, Thorup AC, Overgaard K, Jeppesen PB. High intensity interval training improves glycaemic control and pancreatic $\beta$ cell function of type 2 diabetes patients. PLoS One (2015) 10(8):e0133286. doi:10.1371/journal. pone. 0133286

70. Cassidy S, Thoma C, Hallsworth K, Parikh J, Hollingsworth KG, Taylor R, et al. High intensity intermittent exercise improves cardiac structure and function and reduces liver fat in patients with type 2 diabetes: a randomised controlled trial. Diabetologia (2016) 59(1):56-66. doi:10.1007/s00125-015-3741-2

71. Trost SG, Owen N, Bauman AE, Sallis JF, Brown W. Correlates of adults' participation in physical activity: review and update. Med Sci Sports Exerc (2002) 34(12):1996-2001. doi:10.1097/00005768-200212000-00020

72. Little JP, Gillen JB, Percival ME, Safdar A, Tarnopolsky MA, Punthakee $\mathrm{Z}$, et al. Low-volume high-intensity interval training reduces hyperglycemia and increases muscle mitochondrial capacity in patients with type 2 diabetes. J Appl Physiol (2011) 111(6):1554-60. doi:10.1152/ japplphysiol.00921.2011

73. Francois ME, Durrer C, Pistawka KJ, Halperin FA, Chang C, Little JP. Combined interval training and post-exercise nutrition in type 2 diabetes: a randomized control trial. Front Physiol (2017) 8:528. doi:10.3389/fphys. 2017.00528

74. Revdal A, Hollekim-Strand SM, Ingul CB. Can time efficient exercise improve cardiometabolic risk factors in type 2 diabetes? A pilot study. J Sports Sci Med (2016) 15(2):308.

75. Little JP, Safdar A, Bishop D, Tarnopolsky MA, Gibala MJ. An acute bout of high-intensity interval training increases the nuclear abundance of PGC$1 \alpha$ and activates mitochondrial biogenesis in human skeletal muscle. Am 
J Physiol Regul Integr Comp Physiol (2011) 300(6):R1303-10. doi:10.1152/ ajpregu.00538.2010

76. Little JP, Jung ME, Wright AE, Wright W, Manders RJ. Effects of highintensity interval exercise versus continuous moderate-intensity exercise on postprandial glycemic control assessed by continuous glucose monitoring in obese adults. Appl Physiol Nutr Metab (2014) 39(7):835-41. doi:10.1139/ apnm-2013-0512

77. Martinez N, Kilpatrick MW, Salomon K, Jung ME, Little JP. Affective and enjoyment responses to high-intensity interval training in overweight-toobese and insufficiently active adults. J Sport Exerc Psychol (2015) 37(2): 138-49. doi:10.1123/jsep.2014-0212

78. Little JP, Francois ME. High-intensity interval training for improving postprandial hyperglycemia. Res Q Exerc Sport (2014) 85(4):451-6. doi:10.1080/ 02701367.2014.963474

79. MacInnis MJ, Gibala MJ. Physiological adaptations to interval training and the role of exercise intensity. J Physiol (2016) 595(9):2915-30. doi:10.1113/ JP273196

80. Jiménez-Pavón D, Lavie CJ. Response: commentary: high-intensity intermittent training vs. moderate-intensity intermittent training: is it a matter of intensity or intermittent efforts? Front Physiol (2017) 8:526. doi:10.3389/ fphys.2017.00526

81. Kraegen EW, Clark PW, Jenkins AB, Daley EA, Chisholm DJ, Storlien LH. Development of muscle insulin resistance after liver insulin resistance in high-fat-fed rats. Diabetes (1991) 40(11):1397-403. doi:10.2337/diabetes. 40.11.1397

82. Lamont B, Waters M, Andrikopoulos S. A low-carbohydrate high-fat diet increases weight gain and does not improve glucose tolerance, insulin secretion or $\beta$-cell mass in NZO mice. Nutr Diabetes (2016) 6(2):e194. doi:10.1038/ nutd.2016.2

83. Vessby B, Uusitupa M, Hermansen K, Riccardi G, Rivellese AA, Tapsell LC, et al. Substituting dietary saturated for monounsaturated fat impairs insulin sensitivity in healthy men and women: the KANWU study. Diabetologia (2001) 44(3):312-9. doi:10.1007/s001250051620

84. Riccardi G, Giacco R, Rivellese A. Dietary fat, insulin sensitivity and the metabolic syndrome. Clin Nutr (2004) 23(4):447-56. doi:10.1016/j.clnu. 2004.02.006

85. Numao S, Kawano H, Endo N, Yamada Y, Konishi M, Takahashi M, et al. Short-term low carbohydrate/high-fat diet intake increases postprandial plasma glucose and glucagon-like peptide-1 levels during an oral glucose tolerance test in healthy men. Eur J Clin Nutr (2012) 66(8):926-31. doi:10.1038/ ejen.2012.58

86. Wan Z, Durrer C, Mah D, Simtchouk S, Robinson E, Little JP. Reduction of AMPK activity and altered MAPKs signalling in peripheral blood mononuclear cells in response to acute glucose ingestion following a short-term high fat diet in young healthy men. Metabolism (2014) 63(9):1209-16. doi:10.1016/j.metabol.2014.06.007

87. Thomas CD, Peters JC, Reed GW, Abumrad NN, Sun M, Hill J. Nutrient balance and energy expenditure during ad libitum feeding of high-fat and high-carbohydrate diets in humans. Am J Clin Nutr (1992) 55(5):934-42.

88. Schrauwen P, van Marken Lichtenbelt W, Saris W, Westerterp KR. Changes in fat oxidation in response to a high-fat diet. Am J Clin Nutr (1997) 66(2):276-82.

89. Corpeleijn E, Saris WH, Blaak EE. Metabolic flexibility in the development of insulin resistance and type 2 diabetes: effects of lifestyle. Obes Rev (2009) 10(2):178-93. doi:10.1111/j.1467-789X.2008.00544.X

90. Nappo F, Esposito K, Cioffi M, Giugliano G, Molinari AM, Paolisso G, et al. Postprandial endothelial activation in healthy subjects and in type 2 diabetic patients: role of fat and carbohydrate meals. J Am Coll Cardiol (2002) 39(7):1145-50. doi:10.1016/S0735-1097(02)01741-2

91. Dansinger ML, Gleason JA, Griffith JL, Selker HP, Schaefer EJ. Comparison of the Atkins, Ornish, Weight Watchers, and Zone diets for weight loss and heart disease risk reduction: a randomized trial. JAMA (2005) 293(1):43-53. doi:10.1001/jama.293.1.43

92. Gillen J, Little J, Punthakee Z, Tarnopolsky M, Riddell M, Gibala M. Acute high-intensity interval exercise reduces the postprandial glucose response and prevalence of hyperglycaemia in patients with type 2 diabetes. Diabetes Obes Metab (2012) 14(6):575-7. doi:10.1111/j.1463-1326.2012.01564.x

93. Francois ME, Baldi JC, Manning PJ, Lucas SJ, Hawley JA, Williams MJ, et al. 'Exercise snacks' before meals: a novel strategy to improve glycaemic control in individuals with insulin resistance. Diabetologia (2014) 57(7):1437-45. doi:10.1007/s00125-014-3244-6

94. Sheard NF, Clark NG, Brand-Miller JC, Franz MJ, Pi-Sunyer FX, MayerDavis E, et al. Dietary carbohydrate (amount and type) in the prevention and management of diabetes. Diabetes Care (2004) 27(9):2266-71. doi:10.2337/ diacare.27.9.2266

95. Gutniak M, Grill V, Efendlć S. Effect of composition of mixed meals-lowversus high-carbohydrate content-on insulin, glucagon, and somatostatin release in healthy humans and in patients with NIDDM. Diabetes Care (1986) 9(3):244-9. doi:10.2337/diacare.9.3.244

96. Papakonstantinou E, Triantafillidou D, Panagiotakos D, Iraklianou S, Berdanier C, Zampelas A. A high protein low fat meal does not influence glucose and insulin responses in obese individuals with or without type 2 diabetes. J Hum Nutr Diet (2010) 23(2):183-9. doi:10.1111/j.1365-277X. 2009.01020.x

97. Gill JM, Al-Mamari A, Ferrell WR, Cleland SJ, Packard CJ, Sattar N, et al. Effects of prior moderate exercise on postprandial metabolism and vascular function in lean and centrally obese men. J Am Coll Cardiol (2004) 44(12):2375-82. doi:10.1016/j.jacc.2004.09.035

98. Padilla J, Harris RA, Fly AD, Rink LD, Wallace JP. The effect of acute exercise on endothelial function following a high-fat meal. Eur J Appl Physiol (2006) 98(3):256-62. doi:10.1007/s00421-006-0272-z

99. Tyldum GA, Schjerve IE, Tjønna AE, Kirkeby-Garstad I, Stølen TO, Richardson RS, et al. Endothelial dysfunction induced by post-prandial lipemia: complete protection afforded by high-intensity aerobic interval exercise. J Am Coll Cardiol (2009) 53(2):200-6. doi:10.1016/j.jacc.2008. 09.033

100. Deanfield JE, Halcox JP, Rabelink TJ. Endothelial function and dysfunction testing and clinical relevance. Circulation (2007) 115(10):1285-95. doi:10.1161/CIRCULATIONAHA.106.652859

101. Inaba Y, Chen JA, Bergmann SR. Prediction of future cardiovascular outcomes by flow-mediated vasodilatation of brachial artery: a meta-analysis. Int J Cardiovasc Imaging (2010) 26(6):631-40. doi:10.1007/s10554-010-9616-1

102. O'Keefe JH, Bell DS. Postprandial hyperglycemia/hyperlipidemia (postprandial dysmetabolism) is a cardiovascular risk factor. Am J Cardiol (2007) 100(5):899-904. doi:10.1016/j.amjcard.2007.03.107

103. Wei-Chuan T, Yi-Heng L, Chih-Chan L, Ting-Hsing C, Jyh-Hong C. Effects of oxidative stress on endothelial function after a high-fat meal. Clin Sci (2004) 106(3):315-9. doi:10.1042/CS20030227

104. Herieka M, Erridge C. High-fat meal induced postprandial inflammation. Mol Nutr Food Res (2014) 58(1):136-46. doi:10.1002/mnfr.201300104

105. Ceriello A, Taboga C, Tonutti L, Quagliaro L, Piconi L, Bais B, et al. Evidence for an independent and cumulative effect of postprandial hypertriglyceridemia and hyperglycemia on endothelial dysfunction and oxidative stress generation. Circulation (2002) 106(10):1211-8. doi:10.1161/01. CIR.0000027569.76671.A8

106. Steer P, Sarabi DM, Karlström B, Samar B, Berne C, Vessby B, et al. The effect of a mixed meal on endothelium-dependent vasodilation is dependent on fat content in healthy humans. Clin Sci (2003) 105(1):81-7. doi:10.1042/ CS20020327

107. Esser D, Oosterink E, Op’t Roodt J, Henry RM, Stehouwer CD, Müller M, et al. Vascular and inflammatory high fat meal responses in young healthy men; a discriminative role of IL-8 observed in a randomized trial. PLoS One (2013) 8(2):e53474. doi:10.1371/journal.pone.0053474

108. Tjønna AE, Rognmo $\varnothing$, Bye A, Stølen TO, Wisløff U. Time course of endothelial adaptation after acute and chronic exercise in patients with metabolic syndrome. J Strength Cond Res (2011) 25(9):2552-8. doi:10.1519/ JSC.0b013e3181fb4809

109. Ross R. Does exercise without weight loss improve insulin sensitivity? Diabetes Care (2003) 26(3):944-5. doi:10.2337/diacare.26.3.944

110. Uusitupa M, Lindi V, Louheranta A, Salopuro T, Lindström J, Tuomilehto J. Long-term improvement in insulin sensitivity by changing lifestyles of people with impaired glucose tolerance. Diabetes (2003) 52(10):2532-8. doi:10.2337/diabetes.52.10.2532

111. Giannopoulou I, Ploutz-Snyder L, Carhart R, Weinstock R, Fernhall B, Goulopoulou $\mathrm{S}$, et al. Exercise is required for visceral fat loss in postmenopausal women with type 2 diabetes. J Clin Endocrinol Metab (2005) 90(3):1511-8. doi:10.1210/jc.2004-1782 
112. Okura T, Nakata Y, Lee D, Ohkawara K, Tanaka K. Effects of aerobic exercise and obesity phenotype on abdominal fat reduction in response to weight loss. Int J Obes (2005) 29(10):1259-66. doi:10.1038/sj.ijo.0803013

113. Ballor DL, Katch V, Becque M, Marks C. Resistance weight training during caloric restriction enhances lean body weight maintenance. Am J Clin Nutr (1988) 47(1):19-25.

114. Foster-Schubert KE, Alfano CM, Duggan CR, Xiao L, Campbell KL, Kong A, et al. Effect of diet and exercise, alone or combined, on weight and body composition in overweight-to-obese postmenopausal women. Obesity (2012) 20(8):1628-38. doi:10.1038/oby.2011.76

115. Anton SD, Karabetian C, Naugle K, Buford TW. Obesity and diabetes as accelerators of functional decline: can lifestyle interventions maintain functional status in high risk older adults? Exp Gerontol (2013) 48(9):888-97. doi:10.1016/j.exger.2013.06.007

116. Park SW, Goodpaster BH, Lee JS, Kuller LH, Boudreau R, De Rekeneire $\mathrm{N}$, et al. Excessive loss of skeletal muscle mass in older adults with type 2 diabetes. Diabetes Care (2009) 32(11):1993-7. doi:10.2337/dc09-0264

117. Fukushima Y, Kurose S, Shinno H, Cao Thu H, Takao N, Tsutsumi H, et al. Importance of lean muscle maintenance to improve insulin resistance by body weight reduction in female patients with obesity. Diabetes Metab J (2016) 40(2):147-53. doi:10.4093/dmj.2016.40.2.147

118. Robinson MM, Dasari S, Konopka AR, Johnson ML, Manjunatha S, Esponda RR, et al. Enhanced protein translation underlies improved metabolic and physical adaptations to different exercise training modes in young and old humans. Cell Metab (2017) 25(3):581-92. doi:10.1016/j. cmet.2017.02.009

119. Kreider RB, Rasmussen C, Kerksick CM, Wilborn C, Taylor L IV, Campbell B, et al. A carbohydrate-restricted diet during resistance training promotes more favorable changes in body composition and markers of health in obese women with and without insulin resistance. Phys Sportsmed (2011) 39(2):27-40. doi:10.3810/psm.2011.05.1893

120. Cartee GD, Young DA, Sleeper MD, Zierath J, Wallberg-Henriksson H, Holloszy J. Prolonged increase in insulin-stimulated glucose transport in muscle after exercise. Am J Physiol Endocrinol Metab (1989) 256(4):E494-9.

121. Hawley JA, Burke LM, Phillips SM, Spriet LL. Nutritional modulation of training-induced skeletal muscle adaptations. J Appl Physiol (2011) 110(3):834-45. doi:10.1152/japplphysiol.00949.2010

122. Leal-Cerro A, Gippini A, Amaya M, Lage M, Mato J, Dieguez C, et al. Mechanisms underlying the neuroendocrine response to physical exercise. J Endocrinol Invest (2003) 26(9):879-85. doi:10.1007/BF03345239

123. Pilegaard H, Osada T, Andersen LT, Helge JW, Saltin B, Neufer PD. Substrate availability and transcriptional regulation of metabolic genes in human skeletal muscle during recovery from exercise. Metabolism (2005) 54(8):1048-55. doi:10.1016/j.metabol.2005.03.008

124. Yeo WK, Paton CD, Garnham AP, Burke LM, Carey AL, Hawley JA. Skeletal muscle adaptation and performance responses to once a day versus twice every second day endurance training regimens. JAppl Physiol (2008) 105(5):1462-70. doi:10.1152/japplphysiol.90882.2008
125. McBride A, Ghilagaber S, Nikolaev A, Hardie DG. The glycogen-binding domain on the AMPK $\beta$ subunit allows the kinase to act as alycogen sensor. Cell Metab (2009) 9(1):23-34. doi:10.1016/j.cmet.2008.11.008

126. Richter EA, Derave W, Wojtaszewski JF. Glucose, exercise and insulin: emerging concepts. J Physiol (2001) 535(2):313-22. doi:10.1111/j.14697793.2001.t01-2-00313.x

127. Pilegaard H, Keller C, Steensberg A, Wulff Helge J, Klarlund Pedersen B, Saltin B, et al. Influence of pre-exercise muscle glycogen content on exercise-induced transcriptional regulation of metabolic genes. J Physiol (2002) 541(1):261-71. doi:10.1113/jphysiol.2002.016832

128. Van Proeyen K, Szlufcik K, Nielens H, Ramaekers M, Hespel P. Beneficial metabolic adaptations due to endurance exercise training in the fasted state. J Appl Physiol (2011) 110(1):236-45. doi:10.1152/japplphysiol.00907. 2010

129. Hansen D, De Strijcker D, Calders P. Impact of endurance exercise training in the fasted state on muscle biochemistry and metabolism in healthy subjects: can these effects be of particular clinical benefit to type 2 diabetes mellitus and insulin-resistant patients? Sports Med (2017) 47(3):415-28. doi:10.1007/s40279-016-0594-X

130. Newsom SA, Schenk S, Thomas KM, Harber MP, Knuth ND, Goldenberg N, et al. Energy deficit after exercise augments lipid mobilization but does not contribute to the exercise-induced increase in insulin sensitivity. J Appl Physiol (2010) 108(3):554-60. doi:10.1152/japplphysiol.01106.2009

131. Cochran AJ, Little JP, Tarnopolsky MA, Gibala MJ. Carbohydrate feeding during recovery alters the skeletal muscle metabolic response to repeated sessions of high-intensity interval exercise in humans. J Appl Physiol (2010) 108(3):628-36. doi:10.1152/japplphysiol.00659.2009

132. Bartlett JD, Louhelainen J, Iqbal Z, Cochran AJ, Gibala MJ, Gregson W, et al. Reduced carbohydrate availability enhances exercise-induced p53 signaling in human skeletal muscle: implications for mitochondrial biogenesis. Am J Physiol Regul Integr Comp Physiol (2013) 304(6):R450-8. doi:10.1152/ajpregu. 00498.2012

133. Sartor F, de Morree HM, Matschke V, Marcora SM, Milousis A, Thom JM, et al. High-intensity exercise and carbohydrate-reduced energy-restricted diet in obese individuals. Eur J Appl Physiol (2010) 110(5):893-903. doi:10.1007/s00421-010-1571-y

Conflict of Interest Statement: The authors declare that the research was conducted in the absence of any commercial or financial relationships that could be construed as a potential conflict of interest.

Copyright (C) 2017 Francois, Gillen and Little. This is an open-access article distributed under the terms of the Creative Commons Attribution License (CC BY). The use, distribution or reproduction in other forums is permitted, provided the original author(s) or licensor are credited and that the original publication in this journal is cited, in accordance with accepted academic practice. No use, distribution or reproduction is permitted which does not comply with these terms. 